\title{
Juventude e violência: trajetórias de vida e políticas públicas
}

\section{Youth and violence: life trajectories and public policies}

\section{Luana I sabelle Cabral dos Santos*}

Universidade Federal do Rio Grande do Norte-UFRN, Natal, Rio Grande do Norte, Brasil

\author{
Andressa Maia de Oliveira** \\ Universidade Federal do Rio Grande do Norte-UFRN, Natal, Rio Grande do Norte, \\ Brasil
}

\section{I lana Lemos de Paiva***}

Universidade Federal do Rio Grande do Norte-UFRN, Natal, Rio Grande do Norte, Brasil

\section{Oswaldo Hajime Yamamoto****}

Universidade Federal do Rio Grande do Norte-UFRN, Natal, Rio Grande do Norte, Brasil

\begin{abstract}
RESUMO
Os jovens têm sido os mais atingidos pela violência. Dados mostram que o número de homicídios entre indivíduos de 15 a 24 anos é maior do que entre outras faixas etárias. Este trabalho objetiva refletir sobre os contextos em que jovens vítimas de homicídios estavam inseridos. Para tanto, realizou-se entrevistas com familiares de sete jovens assassinados em Natal-RN, atendidos pela Coordenadoria de Direitos Humanos e Defesa das Minorias. Discutiram-se questões como: violência e possíveis vetores, políticas públicas, entre outras. Verificou-se que cinco jovens eram do sexo masculino, cinco estavam fora de faixa na escola e todos tinham condições econômicas precárias. Familiares refletiram sobre violência, frequentemente relacionando-a às drogas (uso e/ou tráfico) e sobre ausência de ações governamentais direcionadas à juventude. Ao final, problematizou-se a relação da condição juvenil com sociedade e equipamentos públicos, e a ausência de políticas focalizadas no jovem que busquem resgatar a cidadania dessa população.
\end{abstract}

Palavras-chave: juventude, violência, homicídio, políticas públicas

\section{ABSTRACT}

Data shows that the number of homicides among individuals from 15 to 24 years old is higher than among others ages. This work reflects on the contexts in which the youngsters, victims of homicides were inserted. Interviews were carried out with relatives of seven young murdered at Natal-RN, attended by the Coordenadoria de Direitos Humanos e Defesa das Minorias. The issues discussed included: violence and possible vectors, 
public policies, among others. It was noticed that five youth were male, five were out of school range, and all had poor economic conditions. The relatives reflected about violence, frequently relating it to drugs (abuse or trafficking) and about the absence of governmental actions directed to the youth. It was questioned the relationship relation between the juvenile's conditions and society and the public equipments, and the absence of policies focused on the youth that aim at the citizenship of this population.

Keywords: Youth, violence, homicide, public policy

\section{I ntrodução}

Estudo realizado pela Comissão Interamericana de Direitos Humanos $(\mathrm{ClDH})$ da Organização dos Estados Americanos (OEA), e recentemente divulgado, indica que os países latino-americanos apresentam os índices de criminalidade mais altos do mundo, sendo os jovens o grupo mais afetado, como vítimas e como algozes (DELI NQUÊNCIA, 2010), confirmando a tese de Pinheiro (1997) sobre a escalada da violência relacionada a jovens nas grandes cidades da América Latina.

Considerando que a população jovem no Brasil gira em torno de 33 milhões de indivíduos, ou seja, $20 \%$ da população brasileira (INSTITUTO BRASILEIRO DE GEOGRAFIA E ESTATíSTICA, 2007), e que desses, $53 \%$ vivem em famílias com renda per capita entre meio e dois salários mínimos, e 30,6\%, até meio salário mínimo, fica evidenciada a dimensão social desse problema. Embora não seja possível estabelecer conexões mecânicas, o alto índice de jovens pobres envolvidos em episódios de violência revela a existência de um elo entre a violência e a pobreza. Em localidades pobres de São Paulo, para mencionar um exemplo, há registros de 222 homicídios de jovens entre 15 e 24 anos para cada 100.000 habitantes, ou seja, dez vezes mais que a média nacional (PINHEIRO, 1997).

Uma questão que envolve uma parcela tão significativa da população exige a consideração das formas de atenção a essa juventude que está sendo morta, que não é foco de cuidado e que é, não raras vezes, responsabilizada pela própria situação e condição (Adorno, 2002). Além disso, esses jovens que estão sendo "exterminados" tem cor, sexo, situação social e localização definidos, revelando uma das faces da dinâmica de desigualdade e injustiças sociais no Brasil (PERES; CARDIA; SANTOS, 2006).

O Brasil, a exemplo de outras nações latino-americanas, apresenta as marcas históricas do elitismo, do autoritarismo e da exclusão, que associada à criminalização das camadas mais vulneráveis e ao descaso na promoção e garantia de direitos à população produz um cenário no qual se acentua a desigualdade social, criando verdadeiros abismos sociais. 
A permanência desse quadro também pode expressar a escassez do Estado, em suas mais diversas funções, seja como interventor, por meio da elaboração de políticas sociais, seja como mediador de conflitos e contradições, através dos seus aparatos e instituições de controle. Nesse sentido, o Estado, muitas vezes, só se torna visível quando assume medidas opressoras (LOPES; ADORNO; MALFITANO; TAKEITI; SILVA; BORBA, 2008).

A cada ano, no Brasil, cerca de 26 mil crianças e jovens entre 10 e 19 anos morrem por causas múltiplas (acidentes, suicídios, doenças relacionadas à gravidez, problemas crônicos de saúde, etc.) e $70 \%$ das causas das mortes de jovens deve-se a causas externas (homicídios, acidentes de trânsito, suicídio, etc.). Especificamente em relação aos homicídios, o país ocupa o terceiro lugar no mundo em assassinato de jovens entre 15 e 24 anos (ORGANIZAÇÃO DAS NAÇÕES UNIDAS PARA A EDUCAÇÃO, A CIÊNCIA E A CULTURA, 2004).

Entre 1991 e 2000, a taxa de homicídio juvenil aumentou de 66,5 para 98,8 por 100 mil mortos (DAYRELL; CARRANO, 2003), número que ultrapassa as taxas de países em guerra declarada. Essa violência atinge os jovens das periferias e bairros pobres em maior proporção do que jovens que moram em bairros nobres, com maior segurança tanto privada, quanto pública. Além disso, segundo os dados do Instituto de Pesquisa Econômica Aplicada - IPEA (CASTRO; AQUINO; ANDRADE, 2009), a cada jovem branco vítima de homicídio, dois jovens negros são mortos. Esse dado é reforçado em estudos, como o de Soares (2004), Sant'Anna; Aerts e Lopes (2005), que demonstram que o risco pessoal e social é maior para homens jovens e negros.

Outro ponto que merece consideração diz respeito às percepções e representações da sociedade e do próprio segmento juvenil que se reflete na tensão entre protagonismo e vitimização. Isto é, "cristalizou-se um imaginário social no qual se associa o segmento juvenil - em especial as classes populares - à condição de protagonistas da violência e, mais ainda, à constituição de uma ameaça indiscriminada a toda a sociedade" (BRASIL, 2009a, p. 20). Dessa forma, ocorre uma criminalização dessa juventude, que muitas vezes, acaba assumindo esse papel e passando a adotar comportamentos que reforçam essa ideia.

Segundo a Secretaria Especial de Direito Humanos - SEDH (BRASIL, 2009 b), os homicídios representam $46 \%$ das causas de morte dos cidadãos brasileiros da faixa etária entre 12 e 18 anos, sendo a maior parcela dos homicídios cometidos com arma de fogo, o que revela um dado grave que diz respeito ao alto índice de resolução de conflitos pessoais ou interpessoais por meio de armas de fogo. Esses dados da SEDH apontam que, desde 1998, o índice de homicídios, suicídios ou acidentes ocasionados por arma de fogo, só aumenta, sendo o 
homicídio o principal motivo da utilização desse instrumento. Quando se relaciona juventude a armas de fogo, os dados desse mapeamento revelam que $31,2 \%$ de todas as mortes de jovens, no ano de 2002, foram causadas por armas de fogo, sendo que em alguns Estados (Rio de Janeiro, Pernambuco e Espírito Santo), metade das mortes teve a arma de fogo como causa (WAISELFISZ, 2004).

A situação do estado do Rio Grande do Norte não é muito diversa: os índices de mortalidade de jovens são alarmantes. De acordo com registros da Coordenadoria de Direitos Humanos e Defesa das Minorias do Rio Grande do Norte (CODEM-RN), de janeiro a outubro de 2009 foram mortas 270 pessoas entre 15 e 24 anos. Dessas, 255 são do sexo masculino, corroborando a literatura que indica serem os homens jovens os mais afetados pela violência. Isso inclui tanto a juventude pobre quanto as classes média e alta, o que sugere que comportamentos de risco e/ou violentos são parte do cotidiano dos jovens, independente de sua classe social, ainda que a ocorrência, e consequentemente a culpabilização, seja maior dentre a juventude pobre.

Nesse contexto de violência, descaso e criminalização, conhecer o contexto de vida dos jovens e de suas famílias que vivenciaram cotidianos de violência pode auxiliar na tarefa de promover uma aproximação com a realidade vivenciada por esse público, pensando em ações contextualizadas. É onde se insere o objetivo do presente estudo: abordar a trajetória de vida de jovens que foram vítimas de homicídio, pela perspectiva de seus familiares, investigando o contexto no qual esses jovens estão inseridos, como esse contexto é significado pelas famílias dos jovens mortos por homicídio, se as políticas públicas eventualmente presentes são conhecidas por essas famílias e por esses jovens, e como essas políticas chegam a essa população.

\section{Materiais e Métodos}

Inicialmente, foi realizado um levantamento das fichas e dos cadastros de famílias atendidas pela CODEM-RN, que tiveram algum parente jovem assassinado. Nessa etapa, foi realizada uma caracterização sociodemográfica dessas famílias, com as informações contidas nas fichas. Em seguida, foram feitos contatos com os familiares, solicitando a sua participação e anuência pela assinatura de um Termo de Consentimento Livre e Esclarecido (TCLE) contendo informações sobre o tema, o objetivo da pesquisa, a assinatura das pesquisadoras e o contato. Os participantes retiveram uma cópia do documento e garantia-se total anonimato e sigilo.

Participaram do estudo familiares de sete dos onze jovens vítimas de homicídio que foram atendidos pela CODEM, a saber, cinco mães, um 
pai e uma companheira. O familiar foi definido como o participante do estudo pelo fato de se constituir em fonte privilegiada de informações sobre a vida do jovem.

Foram realizadas entrevistas semiestruturadas, ao longo do segundo semestre do ano de 2009, a partir de um roteiro composto por questões norteadoras que abarcavam informações gerais dos participantes (para complementar e/ou atualizar/conferir as informações da ficha da família), aspectos específicos sobre o jovem (escolaridade, vínculo empregatício, participação em movimentos sociais, entre outros) e perguntas relativas à percepção do familiar em relação a questões como violência, atuação da polícia, políticas públicas, entre outras.

As entrevistas foram transcritas e organizadas em banco de dados eletrônico no software QDA Miner versão 3.2. As falas dos familiares foram agrupadas a partir da leitura do conjunto das transcrições. Inicialmente, foram reunidas as falas que versavam sobre a violência em geral. Nesse conjunto, foi percebido que o que estava por trás eram explicações para a violência, tanto no âmbito individual, quanto social. Por isso, passaram a integrar um bloco denominado "explicações para a violência". O segundo agrupamento diz respeito à questão das políticas públicas. Aqui foram incluídas as falas que faziam referência ao papel do Estado na proteção do jovem, ao descaso dos aparatos estatais na questão da violência, às falhas das políticas públicas e à falta de apoio aos familiares do jovem vítima de homicídio.

\section{Resultados e Discussão}

Os resultados serão apresentados em três blocos. O primeiro consiste na caracterização de dados sociodemográficos e de contexto de vida dos jovens. Na segunda parte são apresentadas as explicações acerca da violência. Por último, são feitas considerações sobre as políticas públicas, discutindo a presença (ou ausência) das políticas no contexto de vida dos jovens e de suas famílias e problematizando a insuficiência das políticas ofertadas à população juvenil.

\subsection{Breve caracterização e contexto de vida dos jovens vítimas de homicídios}

O Quadro 1 sintetiza informações sobre as características e o contexto de vida desses jovens. 
Luana Isabelle Cabral dos Santos, Andressa Maia de Oliveira, Ilana Lemos de Paiva, Oswaldo Hajime Yamamoto Juventude e violência

Quadro 1 - Caracterização sociodemográfica dos J ovens

\begin{tabular}{|c|c|c|c|c|c|c|c|c|}
\hline CASO & IDADE & SEXo & ETNIA & ESCOLARIDADE & $\begin{array}{c}\text { SITUAÇÃO } \\
\text { DE } \\
\text { TRABALHO }\end{array}$ & $\begin{array}{c}\text { RENDA } \\
\text { (SM) }\end{array}$ & $\begin{array}{c}\text { ESTADO } \\
\text { CIVIL }\end{array}$ & BAIRRO \\
\hline T & 23 & M & Negra & $\begin{array}{c}\text { Fundamental } \\
\text { Incompleto }\end{array}$ & Empregado & 1 a 2 & Solteiro & Rocas \\
\hline Z & 15 & $\mathrm{~F}$ & Parda & NI & Estudante & $\begin{array}{c}\text { Menos } \\
\text { de } 1\end{array}$ & Solteira & Santos Reis \\
\hline I & 22 & M & Parda & $\begin{array}{c}\text { Fundamental } \\
\text { Completo }\end{array}$ & Outros & Outros & Casado & $\begin{array}{c}\text { Nova } \\
\text { Descoberta }\end{array}$ \\
\hline E & 21 & M & Parda & Médio Incompleto & Empregado & 1 a 2 & Solteiro & $\begin{array}{c}\text { Assentamento/ } \\
\text { Interior }\end{array}$ \\
\hline G & 20 & M & Parda & $\begin{array}{c}\text { Fundamental } \\
\text { Incompleto }\end{array}$ & Estudante & $\begin{array}{c}\text { S/ } \\
\text { mendi- } \\
\text { mento }\end{array}$ & Solteiro & $\begin{array}{c}\text { Cid. Da } \\
\text { Esperança }\end{array}$ \\
\hline A & 22 & M & Negra & $\begin{array}{c}\text { Fundamental } \\
\text { Incompleto }\end{array}$ & Empregado & $\begin{array}{c}1 \text { a } 2 \\
\text { Uniáo } \\
\text { Estável }\end{array}$ & $\begin{array}{c}\text { N. Sa da } \\
\text { Apresentação }\end{array}$ \\
\hline R & 15 & $\mathrm{~F}$ & Parda & Médio Incompleto & Estudante & $\begin{array}{c}\text { S/ - } \\
\text { Rendi- } \\
\text { mento }\end{array}$ & Solteira & Bom Pastor \\
\hline
\end{tabular}

Os dados mostram que cinco dos jovens eram do sexo masculino e apenas dois do sexo feminino. Esse dado não é uma mera casualidade; reflete o quadro do país, no qual os homens jovens são a parcela da população que mais se envolve em situações de violência e são as maiores vítimas de homicídios. Esse fato pode encontrar raízes na cultura masculina de nossa sociedade. Ela está permeada por uma série de modelos estereotipados de masculinidade, que associam ao homem a ideia da violência e se faz presente tanto na educação recebida em casa, quanto na pressão social vivenciada na escola, nos grupos de amigos e pela mídia. Essa imagem socialmente predominante condiciona grande parte do comportamento desses jovens, que incorporam no seu cotidiano a cultura da agressão, fazendo uso da demonstração da força, da disputa de poder em grupos, entre outros (SANT'ANNA; AERTS; LOPES, 2005). Tal conjuntura predispõe os jovens do sexo masculino a maiores situações de risco em relação à violência do que as mulheres.

Refletindo sobre a questão da cor, verificou-se que nenhum jovem em questão era da cor branca (dois deles eram negros e os outros cinco pardos). Essa informação se mostra de acordo com estudos de Sant'Anna; Aerts e Lopes (2005), revelando que a proporção de indivíduos negros e pardos assassinados é sempre maior do que a de indivíduos brancos, indicando, assim, que a violência estrutural atinge mais os negros e pardos por pertencerem a contextos socialmente mais vulneráveis.

Um aspecto fundamental para a compreensão desse quadro que estamos delineando diz respeito à vizinhança, questão já assinalada por Pinheiro (1997). Os bairros nos quais esses jovens moravam estão distribuídos nas quatro zonas/distritos de Natal e um deles, 
num assentamento em Lajes (interior do RN). De acordo com as informações contidas nas fichas de atendimento da CODEM-RN, são bairros que apresentam altos índices de violência e de homicídios índices coletados a partir de dados fornecidos pelo Instituto Técnico e Científico de Polícia (ITEP-RN) à CODEM. São, também, considerados pobres, onde se tem pouco investimento de recursos estatais e uma ausência de áreas de lazer e de convivência comunitária.

De um modo geral, esses bairros populares encontram-se desassistidos. Ocorre, muitas vezes, o fenômeno da invisibilidade, que acaba impossibilitando o acesso da juventude às políticas públicas e ações sociais e, ao mesmo tempo, permite e incentiva sua entrada no tráfico, como passaporte à visibilidade e permitindo o acesso ao consumo de objetos-símbolos de determinados grupos juvenis (SCHMIDT, 2007). Muitas vezes, são nesses contextos que o jovem encontra a "ilusão" da participação e o sentimento de pertencimento a um grupo, que assim como ele, possuem desejos, sonhos e vontades, em comum (SOARES, 2004).

As informações referentes à escolaridade mostram que, apesar de cinco desses jovens terem mais de 20 anos, nenhum deles tinha sequer o ensino médio; três deles, com mais de 20 anos, não chegaram a concluir o ensino fundamental. Três dos jovens não mantinham mais vínculo com a escola e apenas trabalhavam. A renda desses jovens era baixa: dos que trabalhavam, um ganhava menos de um salário mínimo e três entre um e três SM. De acordo com Dayrell e Carrano (2003), o sentimento de fracasso do jovem ao procurar trabalho remunerado e não encontrar pode ser uma porta de abertura para outros sentimentos e possibilidades, como o ganho pela via do crime.

Esses dados compõem o quadro socioeconômico no qual estão inseridos esses jovens: morando em bairros pobres, sem acesso à escola de qualidade, com baixa renda. As análises raramente levam em conta essas qualificações (PINHEIRO, 1997; ABRAMOVAY; CASTRO; PINHEIRO; LIMA; MARTINELLI, 2002). O que se percebe é que essa população se encontra em situação de vulnerabilidade individual, pois, muitas vezes, se envolve em situações que a colocam em risco, como o uso e/ou tráfico de drogas, e em vulnerabilidade social (SANT'ANNA; AERTS; LOPES, 2005), uma vez que os equipamentos estatais não têm ação e efetividade na comunidade e os jovens buscam sua "ascensão social" por outros meios (cf. PINHEIRO, 1997).

A falta de assistência do Estado, a precariedade do sistema escolar, de saúde e de assistência social e a própria violência presente em todas as comunidades, principalmente nas comunidades pobres, são desconsideradas ou colocadas em segundo plano. No entanto, esses são fatores imprescindíveis e o que se tem é que essa situação precária, de vulnerabilidade, na qual na maioria das vezes a 
população não tem acesso ao mínimo básico para a sobrevivência, dá poucas condições de desenvolvimento positivo. Com isso, fica evidente que a falta de acesso e perspectivas representa uma problemática que interfere no desenvolvimento, nas descobertas e na própria formação dos jovens.

Os dados aqui apresentados sugerem que esses jovens assassinados se enquadram no perfil da juventude que vem sendo morta no nosso país, isto é, os jovens vítimas de homicídios são pobres, com pouca instrução/escolaridade, homens, negros e pardos (SOARES, 2004). Por sua vez, essa confirmação revela uma realidade cruel e denunciadora das contradições existentes nas relações sociais.

\subsection{A respeito da explicação para a violência}

O segundo bloco de análises se refere às explicações para a violência a partir do entendimento dos familiares. Nesse bloco surgiram respostas que atribuíam a violência a fatores externos ao jovem, como presença de drogas no bairro, ineficiência das políticas públicas, conivência do estado com atividades ilícitas. E outras respostas que atribuíam a violência a condutas e/ou condições "internas" do jovem ou da família, como a falha na educação familiar, o envolvimento do jovem com drogas e a concepção naturalizante da violência (que atribui determinadas características e comportamentos à fatores inatos e aspectos biológicos do jovem). Para compreender esse bloco de análises, toma-se como questão-base a reflexão sobre "o que causa a violência?".

A referência às drogas é uma constante, seja apontando-as como causa para violência de maneira geral, seja revelando o envolvimento do jovem, ou denunciando a presença das mesmas nas comunidades. Nos casos relatados, essa questão está presente em todos, o que torna mais visível ainda a existência de uma relação entre drogas, violência e comportamentos de risco. Ou seja, a droga está associada a situações violentas ou atos violentos que podem culminar em agressões e mortes de jovens. Essa relação fica clara nos seguintes trechos:

Ele começou e o primeiro passo foi o álcool e foi no crescendo no crescendo e conheceu o crack, apesar dele passar pouco tempo usando o crack, mas o pouco tempo que ele passou no crack foi terrível, na maconha ele ficava tranqüilo, mas no crack ele ficava feito um bicho. (CG)

O que tá causando a violência hoje, realmente, é as drogas né? Eles estão usando muita droga, e pra manter esse vício eles começam a fazer coisas erradas, como roubar, assaltar né? $(\mathrm{Cl})$ 
O que essas falas mostram é a presença intensa e indiscriminada das drogas na vida dos jovens e, consequentemente, da própria família. Elas estabelecem uma relação entre a violência e o consumo de substâncias ilícitas que são oriundas das experiências e das vivências na comunidade e em casa. A juventude tem entrado em contato com as drogas cada vez mais cedo e, muitas vezes, esse processo evolui rapidamente para a entrada dos jovens no mundo do tráfico, seja indicando a busca por uma alternativa econômica e de sobrevivência (KODATO; SILVA, 2000), seja significando a possibilidade da inserção social em um grupo.

Nesse sentido, ao consumo de drogas ou qualquer tipo de envolvimento com ela associa-se uma série de comportamentos que colocam esses jovens em risco. Por exemplo, uma vez que o jovem se insere no tráfico - situação presente em três casos - fica vulnerável a ações dos traficantes e qualquer desconfiança que surja, pode colocá-lo em perigo. Ademais, o envolvimento com o tráfico de drogas acaba sendo uma das únicas opções para a mobilidade social, bloqueados os caminhos tradicionais (PINHEIRO, 1997).

No entanto, ao se colocar nessa posição, o jovem não previne situações e contextos que o deixa exposto à violência, dentro e fora da comunidade e dos seus grupos. Em um dos casos pesquisados, 0 jovem foi vítima de homicídio, justamente, porque "sabia demais", morto como "queima de arquivo", como ilustrado na seguinte fala:

[...] meu filho conseguiu sair das drogas [...] e quando ele tava limpo todo organizado retomando a vida dele, simplesmente, o pessoal do grupo de extermínio decidiu que ele sabia demais e mataram o meu filho com seis tiros a queima roupa. (CG)

Essa fala pode exemplificar o quanto uma vez envolvido com o tráfico, o destino do jovem, muitas vezes, já é definido, por mais que ele tente se desvencilhar da situação.

Outro ponto levantado pelos participantes diz respeito à ação da polícia nos bairros. De acordo com os entrevistados, quando há policiamento, ele tende a ter um caráter violento ou corrupto, com a participação de policiais em atividades ilícitas. Essa situação gera mais medo e insegurança na população, uma vez que a instituição que é responsável por dar algum tipo de conforto e segurança é ela mesma participante de atividades ilícitas e um dos atores da violência, como demonstra a fala abaixo:

Essas bocas de fumo é porque as autoridades não querem acabar, porque todas essas bocas de fumo quando dá um determinado horário tem carro da policia pegando dinheiro, isso é uma coisa visível, que todo mundo sabe, o governador sabe, o presidente, todo mundo sabe. (CR) 
[...] a ação da policia é uma bomba sabe? Porque se você tiver dinheiro eles pegam seu dinheiro. (CT)

A questão da polícia abre espaço para a discussão da precariedade do sistema de segurança pública. Esses profissionais, em alguns casos, não recebem o treinamento e capacitação adequada para atuar nesses contextos e, em outros casos, o baixo salário, a falta de reconhecimento ou a crença na impunidade, acaba sendo um atrativo para a entrada deles na corrupção. A corrupção policial e sua atuação a partir do crime organizado, grupos de extermínios e milícias tem uma longa trajetória no país, herança de uma estrutura de violência patrimonialista, típica dos países ibéricos, e da clandestinização da segurança pública, provenientes das políticas internacionais no período da guerra fria (LEMOS-NELSON, 2006). Uma vez envolvidos nessas atividades ilícitas, a ação truculenta e a própria violência se tornam estratégias para se manter no "esquema" e impor "respeito" através da imposição do medo (LEMOS-NELSON, 2006).

Outro grupo de respostas sugere que a falha na educação familiar pode ser uma explicação para a violência. Essa opinião pode ser evidenciada na seguinte fala: (...) a violência começa dentro de casa, dentro de casa... deixando os filhos muito a vontade... $(\mathrm{Cl})$

Nesse sentido, é importante refletir sobre o papel que a família tem no desenvolvimento do jovem, como primeira esfera de cuidado e proteção do indivíduo. No entanto, é preciso levar em consideração que contextos diversos contribuem para o desenvolvimento desse jovem. A família é mais uma esfera, que tem um papel importante, mas não é exclusivo. Outro tipo de resposta atribui a violência a algo interno ao jovem, demonstrando uma concepção naturalizante da mesma, isto é, a violência e os comportamentos de risco são algo inerente àquele jovem, fazem parte da sua natureza, como é dito:

Ele tinha a índole assim, de pessoa que gostava de adrenalina $[\ldots] .(\mathrm{Cl})$

O que eu acho é que a pessoa já nasce predestinada a certo tipo de coisa. $(\mathrm{Cl})$

A concepção de que o jovem é um ser em formação que está passando por um período de transição que, por sua vez, carrega marcas afirmadas como natureza é recorrente na sociedade capitalista. Nesse sentido, atitudes e comportamentos são tidos como manifestações da essência desse ser e, portanto, são imutáveis. É nesse aspecto que as qualidades e defeitos, como o vigor, a impulsividade, a rebeldia e a agressividade, por exemplo, são tidos como inerentes ao jovem, significando características próprias da sua natureza (COIMBRA; NASCIMENTO, 2005). 
Para alguns autores, como Sant'Anna; Aerts e Lopes (2005) e Lopes et al. (2008), assim como para a Organización Panamericana de la Salud (2002), a violência é constituída por uma multiplicidade de contextos inter-relacionados, não havendo, portanto, como determinar uma causa única para sua ocorrência e, por isso mesmo, exigindo uma força tarefa no seu combate. Ou seja, as formas de enfrentamento dessa questão devem passar pelas esferas nas quais a violência se constitui, levando-se em consideração, então, aspectos biológicos, psicológicos, sociais e ambientais. A fala de um dos familiares explicita essa ideia:

\begin{abstract}
Existe um conjunto de fatores que levam a isso, que é justamente a falta de perspectiva de vida, a falta de oportunidade, a falta dos serviços estarem funcionando, principalmente para os jovens, uma escola pública de qualidade que ofereça esporte, lazer, que ofereça cultura. (CG)
\end{abstract}

Por fim, ao serem inquiridos sobre as ações que pudessem diminuir a violência, os entrevistados demonstraram ter expectativas acerca do papel do Estado em garantir os mínimos necessários ao desenvolvimento saudável da juventude. Isso pode ser ilustrado nos depoimentos como:

[...] é preciso dar mais assistência, [...] estimular o estudo, a educação [...]. (CG)

[...] eu acho que se o povo da prefeitura [...], e se o conselho comunitário visse e fosse falar que podia fazer alguma coisa, pras crianças, "pros" jovens fazerem, estudar, estudar assim, né? Escola não. É projeto, um projeto lá, eu acho que seria bom, mas ninguém liga pra nada [...]. (CG)

Outras possibilidades fazem referência a ações de profissionalização da juventude, já que, para os familiares, o acesso ao trabalho e a uma profissão está relacionado a possibilidades de inserção do jovem na sociedade que o desviem de caminhos de violência, presentes no seu contexto dentro da comunidade. Isso pode ser visualizado na seguinte fala:

Acredito que tem que ter um programa, profissionalizante também, não aquela coisa só de estudo, mas profissionalizante mesmo, que começasse de manhã e só terminasse de noite, que não ficasse com tempo ocioso, porque com tempo ocioso, é que se faz muita besteira, aí um programa desse seria ideal. $(\mathrm{Cl})$

As ações e programas para a juventude obedecem à trajetória das políticas no Brasil, em termos de possuírem um caráter de fragmentação, dispersão e superposição. Muitas dessas ações são 
inscritas na área da assistência social, o que sugere que essa "inscrição significa dar visibilidade e propor as políticas de juventude sempre subordinadas ao tema da questão social" (SPOSITO; CARVALHO E SILVA; SOUZA, 2006). As políticas de trabalho para a juventude apresentam propostas que visam à entrada do jovem no mercado de trabalho por meio de cursos profissionalizantes que são, em sua maioria, profissões subalternizadas, vistas socialmente como "inferiores" e que possuem condições de trabalho precarizadas, com jornadas longas e sem carteira assinada. Nesse sentido, é preciso refletir sobre de que modo as políticas de emprego podem e contribuem de fato para a aquisição de um trabalho digno, com condições saudáveis e de acordo com as especificidades das regiões e comunidades.

Com base nas entrevistas realizadas, é possível conceber que a violência é entendida pelos familiares como um fenômeno que tem múltiplas determinações. Estas são associadas a situações nas quais os indivíduos se encontram vulneráveis por diversos fatores, que vão desde a presença das drogas nas suas comunidades até a ausência de equipamentos estatais e políticas públicas que dêem conta de promover, minimamente, os direitos fundamentais dos indivíduos. $\mathrm{Na}$ tentativa de enfrentamento dessa questão é preciso que se pense em esforços que envolvam os espaços nos quais a juventude circula e busca se inserir, como a escola, e, também, por meio de campanhas de assistência e de saúde, que promovam o esclarecimento e as orientações necessárias tanto aos jovens quanto às suas famílias.

\subsection{Acesso às Políticas Públicas}

As falas dos familiares ilustram um cenário de insuficiência e ausência das políticas - conjunto coerente de intenções do Estado e da sociedade civil que se unem para estabelecer objetivos, diretrizes e estratégias destinados a fomentar e coordenar ações voltadas para o desenvolvimento de determinado segmento da população (CHAVES JUNIOR, 1999). Quando as políticas existem na vida do jovem, são pouco estruturadas no sentido de garantir a amenização ou saída do mesmo de situações de risco e vulnerabilidade pessoal e social, exatamente pela ausência de continuidade e de articulação com outras políticas sociais. Essa superficialidade das ações é relatada na seguinte fala:

[...] nada é feito. Quando é feito, é um negócio superficial, um negócio superficial, vamos botar uma bolsa e você vem aqui uma vez por mês, quer dizer, um negócio muito superficial, tem que ter programas de maior integração, que integre, que ocupe. (CR) 
De forma geral, faltam ações integradas, falta continuidade e falta articulação, isto é, tem-se uma série de ausências, além de que muitas políticas ainda são marcadas por um caráter assistencialista, não promovendo a cidadania e não assegurando os direitos da população vulnerável. Nesse sentido, a concepção acerca dos direitos acaba sendo distorcida, ou seja, a garantia do direito é vista como um favor concedido por "piedade e caridade" àqueles que não têm condições de suprir suas necessidades por si mesmos (LOPES, 1999). Dessa forma, a discussão das causas dessa questão não é colocada em seu devido lugar: como uma questão estrutural da sociedade capitalista, sendo própria e inerente à mesma, permeada pelos jogos de interesses que se desenvolvem no seio da sociedade, determinando de que forma vão se estruturar e se legitimar as relações sociais.

É possível perceber também nas falas, a indignação e a revolta, em parte provocada pela situação "jurídica" do caso do homicídio em si, já que não se vê resolutividade nos processos. Isto é, a burocracia e lentidão no andamento dos inquéritos acabam dificultando o fechamento dos mesmos. Por outro lado, tem-se uma situação em que falta apoio e assistência às famílias, contribuindo para que essas pessoas se sintam, muitas vezes, invisíveis perante o Estado. Essa questão é exemplificada na seguinte fala:

Tudo que você pode imaginar de órgão público que pudesse ajudar a gente nós procuramos, mas não tivemos ajuda, a realidade é essa, nua e crua, não tivemos. (CR).

A própria justiça colabora com esse tipo de mal feito, se houvesse rigidez com um crime desse [...] $O$ inquérito ainda não tinha nem sido aberto $[\ldots](C R)$

Outro ponto a ser destacado diz respeito à falta de estrutura dos equipamentos públicos, quando se diz que a equipe é pequena, que faltam carros para as diligências, que a polícia é despreparada ou quando se observa que: [...] as viaturas não têm combustível, estão quebradas $[\ldots]$ e a gente fica à mercê. $(C R)$

Situações como estas demonstram o quanto é necessário um investimento na segurança pública e o quanto a população se encontra desassistida em seus direitos básicos, de segurança e bemestar. Essa fala ilustra a vulnerabilidade institucional, na qual os jovens se encontram suscetíveis a situações de violência uma vez que residem em regiões também violentas e que são pouco protegidas pelos equipamentos e demais recursos públicos destinados à segurança e cuidado da população (SANT'ANNA; AERTS; LOPES, 2005).

A situação de violência que gerou a morte dos jovens ajuda-nos a problematizar a questão da invisibilidade não só da juventude, mas também da família, na sua maioria, pertencentes às camadas mais 
pauperizadas da população. Se, até a situação ocorrer, o jovem não era usuário de um programa ou ação social e, portanto, não constava como beneficiário, após a ocorrência, a situação de negligência ocorre, agora, com a sua família, como relatado a seguir:

\begin{abstract}
Eu não tive ajuda de ninguém, de policiais, de direitos humanos, ninguém, nada. E eu busquei, eu fui na Oitava [ 8 a Delegacia de Polícia], fui na DCA [Delegacia Especial Defesa da Criança e do Adolescente], fui na DECAP [Delegacia Especializada em Capturas], DEGEPOL [Delegacia Geral de Polícia Civil], eu não tive a ajuda de ninguém. (CR)

[...] três meses depois foi que ligaram pra mim dizendo que tinham conseguido [atendimento psicológico], que era pra ir pra marcar. (CR)
\end{abstract}

Como diz Sant'Anna; Aerts e Lopes (2005), é preciso que se pense na questão da violência integrando as políticas de assistência às políticas de saúde coletiva, de educação e de cultura, na perspectiva de unir esforços no enfrentamento das questões que podem estar relacionadas com a mesma, como o consumo e tráfico de drogas, e priorizando 0 atendimento aos indivíduos jovens vulneráveis, segmento frequentemente esquecido.

É notório, hoje, que as problemáticas da juventude e da violência estão em pauta na agenda política, traduzidas, por exemplo, na criação em 2005 de um Conselho e de uma Secretaria Nacionais de J uventude e, em seguida, com o Plano Nacional de Juventude. Ainda assim, são ações incipientes, que necessitam de um maior incentivo e de uma maior mobilização da sociedade. Como assinala LOPES et al. (2008), são necessárias mais experiências, intervenções, produção de materiais, articulações e parcerias, que contribuam para que mais espaços de participação democrática sejam criados, com o objetivo de possibilitar e estimular o protagonismo e a autonomia dos jovens.

\title{
4 Considerações finais
}

Muitas vezes, na tentativa de se apontar os responsáveis pelos crimes, a sociedade passa a atribuir a culpa aos jovens, considerando-os responsáveis pela situação de desemprego, pela precária inserção no mercado de trabalho, já que não frequentaram a escola e não se capacitaram o suficiente.

Quando se escuta o outro lado, o da população em vulnerabilidade e risco social, é possível refletir que a falta de acesso e perspectivas representa uma problemática que interfere no desenvolvimento, nas descobertas e na própria formação dos jovens. As falas apontam, em sua maioria, para a falta de assistência, da atuação do Estado nas comunidades e de programas que retirem os jovens dos caminhos da 
Luana Isabelle Cabral dos Santos, Andressa Maia de Oliveira, Ilana Lemos de Paiva, Oswaldo Hajime Yamamoto Juventude e violência

violência. Esse tipo de reflexão é expresso nas entrevistas com os familiares:

\begin{abstract}
O que é de jovem hoje é tudo envolvido com droga, tudo morrendo e nada é feito. Quando é feito é um negócio superficial, vamos botar uma bolsa e você vem aqui uma vez por mês, quer dizer um negócio muito superficial, tem que ter programas de maior integração, que integre, que ocupe, porque o caba ocupado dificilmente se vicia em droga (CR).
\end{abstract}

Ao lado da questão das drogas e da falta de assistência e de estratégias que dêem algum tipo de resposta a essa problemática, há a questão da conivência e envolvimento do Estado e da polícia com atividades ilícitas ou a ausência dessas instituições. A ausência de ações sociais e a precariedade das estruturas dos serviços públicos têm uma participação enorme na forma como essa juventude é formada, no modo como ela se relaciona com a sociedade e no modo como ela passa a intervir no seu contexto. Esses processos não são desarticulados, pelo contrário, é a resultante da ineficiência, do descaso e da precariedade que constitui a construção da vida desse segmento.

Diante da complexidade da questão, é indispensável o investimento não somente em políticas sociais como vem sendo discutido ao longo do texto, mas também em pesquisas e intervenções, para que se possa construir um arsenal de técnicas e instrumentos capazes de fornecer subsídios para uma atuação contextualizada e compromissada com os direitos humanos, a promoção da cidadania e do protagonismo, no combate à desigualdade social.

Dessa forma, é relevante acrescentar a importância de intervenções que coloquem em foco o território e a comunidade pertencente a ele, para que se possa pensar em estratégias em que as instituições consigam dialogar e possam ser capazes de promover e assegurar os direitos, a cidadania e a dignidade da população.

\title{
Referências
}

ABRAMOVAY, M.; CASTRO, M. G.; PINHEIRO, L. DE C.; LIMA, F. DE S.; MARTINELLI, C. DA C. Juventude, violência e vulnerabilidade social na América Latina - desafios para políticas públicas. 1. ed. Brasília: UNESCO, 2002.

ADORNO, S. A delinquência juvenil em São Paulo - mitos, imagens e fatos. Pro-Posições, Campinas, v. 13, n. 3, set./dez. 2002.

BRASIL. Índice de Homicídios na Adolescência - análise preliminar dos homicídios em 267 municípios brasileiros com mais de 100 mil habitantes. Brasília: Secretaria Especial de Direitos Humanos, 2009a. 
BRASIL. Ministério do Desenvolvimento Social e Combate à Fome. Adolescências, juventudes e socioeducativo: concepções e fundamentos. Brasília: Ministério do Desenvolvimento Social e Combate à Fome, 2009b.

CASTRO, J. A.; AQUINO, L. M. C. de; ANDRADE, C. C. J uventude e Políticas Sociais no Brasil. Brasília: Instituto de Pesquisa Econômica Aplicada, 2009

CHAVES JUNIOR, E. O. Políticas de Juventude: Revolução Histórica e Definição. In: BRASIL. Cadernos juventude, saúde e desenvolvimento. Brasília: Ministério da Saúde, Secretaria de Políticas de Saúde, 1999.

COIMBRA, C. M. B.; NASCIMENTO, M. L. Ser jovem, ser pobre é ser perigoso?. Revista de Estudios sobre Juventud, México, v. 9, n. 22, p. 338-355, 2005.

DAYRELL, J.; CARRANO, P. C. Jovens no Brasil - difíceis travessias de fim de século e promessas de um outro mundo. 2003. Disponível em:

<http: //www.cmjbh.com.br/arq_Artigos/J OVENS\%20BRASI L\% 20MEX ICO.pdf>. Acesso em: 05 out. 2010.

Delinquência preocupa mais que desemprego na América Latina, diz OEA. Folha.com, São Paulo, 14 jun. 2010. Disponível em: <http://www1.folha.uol.com.br/mundo/750967-delinquencia-

preocupa-mais-que-desemprego-na-america-latina-diz-oea. shtml>.

Acesso em: 04 nov. 2010.

INTITUTO BRASILEIRO DE GEOGRAFIA E ESTATÍSTICA (2007). População jovem no Brasil: a dimensão demográfica. Disponível em:

<http://www.ibge.gov.br/home/estatistica/populacao/populacao_jove m_brasil/comentario1.pdf> Acesso em: 05 out. 2010.

KŌDATO, S.; SILVA, A. P. S. Homicídios de adolescentes: refletindo sobre alguns fatores associados. Psicologia: Reflexão e Crítica, Porto Alegre, v. 13, n. 3, p. 507-515, 2000.

LEMOS-NELSON, A. T. Grupos de extermínio e Accountability em âmbito municipal. Caderno CRH, Salvador, v. 19, n. 47, p. 233-245, 2006.

LOPES, R. E. Cidadania, políticas públicas e terapia ocupacional. 1999. 536 f. Tese (Doutorado em Educação) - Faculdade de Educação da Unicamp, Campinas, 1999.

LOPES, R. E.; ADORNO, R. DE C. F.; MALFITANO, A. P. S.; TAKEITI, B. A.; SILVA, C. R.; BORBA, P. L. DE O. Juventude pobre, violência e cidadania. Saúde e Sociedade, São Paulo, v. 17. n. 3, p. 63-76, set. 2008.

ORGANIZAÇÃO DAS NAÇÕES UNIDAS PARA A EDUCAÇÃO, A CIÊNCIA E A CULTURA. Políticas públicas de/ para/ com as juventudes. Brasília: UNESCO, 2004. 
ORGANIZACIÓN PANAMERICANA DE LA SALUD (OPAS). Informe mundial sobre la violencia y la salud. Washington, D.C.,2002. PERES, M. F. T.; CARDIA, N.; SANTOS, P. C. dos. Homicídios de crianças e jovens no Brasil: 1980-2002. São Paulo: NEV/USP, 2006.

PINHEIRO, P. S. Violência, crime e sistemas policiais em países de novas democracias. Tempo Social, São Paulo, v. 9, n. 1, p. 43-52, 1997.

SANT'ANNA, A; AERTS, D.; LOPES, M. J. Homicídios entre adolescentes no Sul do Brasil: situações de vulnerabilidade segundo seus familiares. Cadernos de Saúde Pública, Rio de Janeiro, v. 21 , n. 1, 120-129, 2005.

SCHMIDT, D. P. Violência como uma expressão da questão social: suas manifestações e seu enfrentamento no espaço escolar. Dissertação de mestrado, Universidade Federal de Santa Maria, Santa Maria, 2007.

SOARES, L. E. Juventude e violência no Brasil contemporâneo. In: NOVAES, R; VANNUCHI, $\mathrm{P}$. (Orgs.). Juventude e sociedade: trabalho, educação, cultura e participação. São Paulo: Fundação Perseu Abramo/ Instituto Cidadania, 2004, p. 130-159.

SPOSITO, M. P.; CARVALHO E SILVA, H. H.; SOUZA, N. A. Juventude e poder local: um balanço de iniciativas públicas voltadas para jovens em municípios de regiões metropolitanas. Revista Brasileira de Educação, São Paulo v.11, n. 32, 238-257, 2006.

WAISELFISZ, J. J. Mapa da Violência IV: os jovens do Brasil. Brasília: UNESCO, Instituto Ayrton Senna, Secretaria Especial dos Direitos Humanos, 2004.

\section{Endereço para correspondência Oswaldo Hajime Yamamoto}

Universidade Federal do Rio Grande do Norte, Centro de Ciências Humanas Letras e Artes, Departamento de Psicologia. Campus Universitário UFRN Lagoa Nova CEP 59078-970 - Natal, Rio Grande do Norte - Brasil - Caixa-Postal: 1622

Endereço eletrônico: oswaldo.yamamoto@gmail.com

Luana I sabelle Cabral dos Santos

Universidade Federal do Rio Grande do Norte

Rua Missionário Joel Carlson, 1989, Capim Macio. CEP: 59082-130 - Natal, Rio Grande do Norte - Brasil.

Endereço eletrônico: luanaicsantos@gmail.com

\section{Andressa Maia de Oliveira}

Universidade Federal do Rio Grande do Norte, Natal, Brasil. Endereço: Alameda Marechal Sucupira, 3693, BI. 41 - Apto 201, Candelária. CEP: 59064-740

Endereço eletrônico: andressamaiaoliveira@gmail.com

I lana Lemos de Paiva

Universidade Federal do Rio Grande do Norte, Centro de Ciências Humanas Letras e Artes, Programa de Pós-Graduação em Psicologia. Campus Universitário Lagoa Nova CEP 59072-970 - Natal, RN - Brasil - Caixa-Postal: 1524

Endereço eletrônico: ilanalp@bol.com.br 
Luana Isabelle Cabral dos Santos, Andressa Maia de Oliveira, Ilana Lemos de Paiva, Oswaldo Hajime Yamamoto Juventude e violência

Recebido em: 09/01/2011

Reformulado em: 09/05/2011

Aceito para publicação em: 11/05/2011

Acompanhamento do processo editorial: Deise Mancebo

\section{Notas}

* Mestranda do Programa de Pós Graduação em Psicologia da Universidade Federal do Rio Grande do Norte.

** Mestranda do Programa de Pós Graduação em Psicologia da Universidade Federal do Rio Grande do Norte.

*** Professora Adjunta do Departamento de Psicologia da Universidade Federal do Rio Grande do Norte. Doutora em Psicologia (UFRN).

**** Professor Titular do Departamento de Psicologia da Universidade Federal do Rio Grande do Norte. Doutor em Educação (USP). 